\title{
(6) OPEN ACCESS \\ Causes of death in people with coeliac disease in England compared with the general population: a competing risk analysis
}

\author{
Alyshah Abdul Sultan, Colin J Crooks, Tim Card, Laila J Tata, Kate M Fleming, Joe West
}

- Additional material is

published online only. To view please visit the journal online (http://dx.doi.org/10.1136/ gutjnl-2014-308285).

Division of Epidemiology and Public Health, City Hospital Campus, The University of Nottingham, Nottingham, UK

\section{Correspondence to} Dr Alyshah Abdul Sultan, Division of Epidemiology and Public Health, City Hospital campus, The University of Nottingham, Room B121, Clinical Science Building 2, Hucknall Road, Nottingham, NG5 1PB, UK:

alyshah.sultan@hotmail.com

Received 19 August 2014 Revised 1 October 2014 Accepted 2 October 2014 Published Online First 24 October 2014

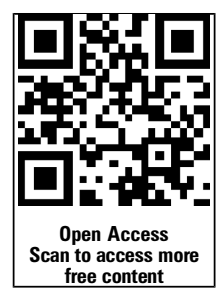

\section{SLinked}

- http://dx.doi.org/10.1136/ gutjnl-2014-308567

\section{CrossMark}

To cite: Abdul Sultan A, Crooks CJ, Card T, et al. Gut 2015;64:1220-1226.

\section{ABSTRACT}

Introduction Quantifying excess cause-specific mortality among people with coeliac disease (CD) compared with the general population accounting for competing risks will allow accurate information to be given on risk of death from specific causes.

Method We identified from the Clinical Practice Research Datalink all patients with CD linked to Office for National Statistics between 1998 and 2012. We selected controls by frequency matching from the registered general practice population within 10-year age bands. We calculated the adjusted cumulative incidence (including adjustment for competing risks) and excess cumulative incidence for different causes of death up to 10 years from diagnosis.

Results of the 10825 patients with CD, 773 died within the study period. The overall mortality rate among patients with $C D$ was $128 / 10000$ person years compared with 153/10 000 in controls (HR=0.94 95\% $\mathrm{Cl} 0.84$ to 1.01 ). We found no overall difference in the cumulative incidence of respiratory disease, digestive disease or cancer related death among cases and controls. The adjusted cumulative incidence of death from cardiovascular deaths was slightly lower compared with those without CD diagnosis (CD $0.32 \%$ vs controls $0.41 \%$ ) with a corresponding excess cumulative incidence of $-0.08 \%(95 \% \mathrm{Cl}-0.13$ to -0.04$)$. However, patients with CD had $0.15 \%$ excess risk $(95 \%$ $\mathrm{Cl} 0.03$ to 0.27 ) of deaths from non-Hodgkin's lymphoma from the general population baseline risk. Conclusions Overall, people with CD have no major excess risk of cancer, digestive disease or respiratory disease related or cardiovascular mortality compared with the general population. These findings should be reassuring to patients with $C D$ and clinicians managing their care.

\section{INTRODUCTION}

Coeliac disease (CD) affects 1\% of the European population yet only approximately $0.2 \%$ is clinically diagnosed. ${ }^{1}{ }^{2}$ Numerous population based studies have addressed the overall mortality risk of people with either diagnosed $\mathrm{CD}$ or serologically positive disease in the general population and shown widely different findings. For instance, a meta-analysis done on the subject reported estimates ranging from a twofold increase in all-cause mortality among patients with CD compared with the general population to no increase in risk at all. ${ }^{3}$ Despite this work, there is a lack of contemporary

\section{Significance of this study}

What is already known on this subject?

- Coeliac disease (CD) affects $1 \%$ of the European population yet only approximately $0.2 \%$ are clinically diagnosed.

- There is a lack of contemporary knowledge about the causes of death among clinically diagnosed patients which may be useful in determining strategies to reduce some of the associated mortality.

- None of the previous studies on the subject have adjusted their analysis for competing risk which may lead to overestimation of associated cause-specific mortality risks.

\section{What are the new findings?}

- By 10 years after diagnosis people with CD have no major excess risk of cancer, digestive disease or respiratory disease related, or cardiovascular mortality compared with the general population.

- Those with CD had a slightly lower cumulative incidence of cardiovascular death following diagnosis.

- Patients with CD had a $0.15 \%$ excess risk of dying from non-Hodgkin's lymphoma up to 10 years post diagnosis.

How might it impact on clinical practice in the foreseeable future?

- Our study provides the most contemporary estimates of the risk of cause-specific mortality among patients with $\mathrm{CD}$. Overall our results should be reassuring to patients and practitioners.

knowledge about the causes of death among clinically diagnosed patients which, if available, may be useful in determining strategies to reduce some of the associated mortality, if any such increases are shown to exist.

Only a few studies ${ }^{4-10}$ have systematically analysed causes of death among people with CD compared with the general population. For instance, small UK based studies from cohorts predominantly diagnosed in the 1980s and 1990s (with less than 200 deaths) ${ }^{6910}$ have consistently reported slightly higher cancer and digestive disease (International 
Classification of Diseases V.2010 (ICD-10); K00-K93) related mortality but have found no statistically significant increased risk of respiratory disease related or cardiovascular mortality compared with the general population. In contrast, Peters et $a l^{7}$ using Swedish inpatient registry data (from 828 deaths in patients diagnosed between 1965 and 1994) reported statistically significant 1.4-fold, threefold and eightfold increased risks of cardiovascular, respiratory disease and digestive disease related mortality, respectively, compared with the control population. Ludvigsson $e t a l^{8}$ conducted the largest study on the subject, also from Sweden, which analysed 3049 deaths of patients diagnosed with CD between 1969 and 2008. Although the study reported a 39\% increased risk of all-cause mortality among patients with CD compared with the general population, and excess of $19 \%, 55 \%$ and $36 \%$ for cardiovascular, neoplasm and respiratory disease related deaths, respectively, their absolute excess risk was low $(0.6,1.1$ and 0.2 per 1000 person years, respectively). Furthermore they also failed to assess whether diagnosis or causes of death had changed over time as their study spanned over 40 years. It is noteworthy that no previous study has adjusted their analysis for competing events (ie, taken into account that patients may die from causes other than those of interest). For instance, if patients with $\mathrm{CD}$ are more likely to die from neoplasm, then their risk of death from other causes will be lower which needs to be taken into account. Not adequately adjusting for competing risks may lead to overestimation of cause-specific mortality risks.

In addition, there may be different patterns of morbidity and mortality among the general population and among people with $\mathrm{CD}$ between countries in which studies are carried out. ${ }^{8} 9$ Finally, there is lack of evidence quantifying the absolute excess risk of specific causes of death compared with the general population. Clearly determining this latter quantity in different countries and healthcare settings is of clinical importance for the purposes of informing patients and clinicians worldwide. Therefore, in this study, using electronic health primary care data linked to national mortality data in England, UK, we have quantified the excess cause-specific mortality among people with $\mathrm{CD}$ by 10 years of diagnosis compared with the general population while accounting for competing risks.

\section{METHODS}

\section{Data source}

We used the Clinical Practice Research Datalink ${ }^{11}$ (CPRD) which is a large longitudinal UK database of computerised primary care (ie, general practice) records. The vast majority of the UK population is registered with general practitioners, ${ }^{12}$ who are responsible for overseeing a patient's medical care which includes coordination of their healthcare from hospital or other secondary care facilities. The CPRD is subjected to quality checks and a practice's data is only used when it is of high enough quality for research. ${ }^{13}$ This is denoted by defining an up-to-standard (UTS) time period for each practice. For the purpose of this study we used the $53 \%$ of CPRD practices for which cause-specific mortality data was available from the Office for National Statistics (ONS) death register. The CPRD data linked to ONS is available from 1998 onwards and covers approximately 3\% of the English population. As this linkage only covers England, practices from Northern Ireland, Wales and Scotland were excluded. This study was approved by the Independent Scientific Advisory Committee of the CPRD (protocol 12_106R).

\section{Study population}

We previously identified people with $\mathrm{CD}$ from the general practice data between 1990 and 2012. ${ }^{1}$ From this population we then selected the subgroup who were registered with primary care practices that had consented linking to the ONS death registry between 1998 and 2012. The diagnosis of CD was based on Read codes representing CD (J690.00 CD; J690.13 Gluten enteropathy; J690z00 CD NOS; J690100 Acquired CD; J690.14 Sprue-nontropical; J690000 Congenital CD). Patients could have a diagnosis of $\mathrm{CD}$ and dermatitis herpetiformis (DH) but not DH alone. Each patient was assigned a date of diagnosis corresponding to the date of their first record of CD.

\section{Comparison group}

Controls were selected from the general population who did not have a diagnosis of $\mathrm{CD}$. For the present study controls were only included if they were registered to primary care practices that had consented to linkage with ONS data (the same criteria as for the cases in our study). We also excluded controls with any record of gluten-free prescription or those with $\mathrm{DH}$ without $\mathrm{CD}$ diagnosis. For this group a random date, 'pseudo diagnosis date' was generated between their date of birth and study end date. We then calculated the age at 'pseudo diagnosis date' for controls and frequency matched them to cases' age at diagnosis in 10-year age bands at a ratio of 10 controls to 1 case.

\section{Follow-up}

An open cohort study design was used within which people could enter and exit at different calendar times and ages. The study start date was defined as the latest of: the start of linked data with ONS (1 April 1998), the date of patient registration with the practice and the 'UTS date' of that practice. For the purpose of this study, we included incidence and prevalent $\mathrm{CD}$ cases as previously defined. ${ }^{1}$ Incident CD cases were followed up from the date of diagnosis rather than their entry date into the database. To sample a comparable follow-up time in the controls, we followed them up from the 'pseudo diagnosis date' rather than their entry date into the database. Failure to do this introduces a bias into the comparison as controls are followed up for a longer time from a younger age than cases. The study end date was defined as the earliest of: the last date for linked primary care data (22 June 2012), the date of patient transfer out from practice, the date of patient's death or the last date of data collection from that practice.

\section{Cause of death}

Information on the underlying cause of death was extracted from the ONS death register which records and codes all deaths occurring in England from the death certificates based on WHO guidelines. ${ }^{14}$ These define causes of death by ICD-10 codes with the main underlying cause established for each death using standardised rules. For this study we analysed the underlying cause of death by the most frequent ICD-10 chapter headings of neoplasms (ICD chapters $\mathrm{C}$ and D), circulatory disease (ICD chapter I: including cerebrovascular and ischaemic heart disease), respiratory disease (ICD chapter J), digestive disease (ICD chapter K) and the remaining less frequent chapter headings grouped together in an 'other causes' category. Causes of death prior to 2001 were coded using ICD-9 and were therefore mapped onto the relevant ICD-10 chapter headings. For our cases and controls, we also used the information on age (at diagnosis date), sex and socioeconomic status (SES, derived from a 
patient's area of residence). Areas of residence within England are ranked according to the Indices of Multiple Deprivation which comprise of a number of indicators covering different aspects of deprivation (housing, employment, income, access to services, education and skills, crime, living environment). These ranked scores are then split into quintiles for the purposes of analysis.

\section{Statistical analysis}

Crude mortality rates

Initially we calculated crude mortality rates among those with and without CD per 10000 person years. These rates where then stratified by the most frequent ICD-10 chapter headings. We also analysed specific causes of death under each ICD-10 chapter heading where there were previously published associations with $\mathrm{CD} .{ }^{9}$

\section{Adjusted analysis}

As previously stated when studying causes of death, the group of survivors (those who do not die during a particular point in time) might not be representative of the initial cohort as deaths from other causes can select out those with relevant risk factors. ${ }^{15}$ One method to adjust for this bias uses cumulative incidence functions (CIFs) (ie, the predicted adjusted cumulative risk of death) from a competing risks model that calculates the probability of overall survival from all causes, combined with the instantaneous hazard of death for each specific cause. We calculated CIFs for each specific cause of death using the basic survival functions and HRs from the adjusted Cox proportional hazards model by 10 years from diagnosis of CD. These models were adjusted for age, sex and SES. We calculated the absolute excess risk for each specific cause of death by taking the difference between the CIFs of those with and without CD. The 95\% CIs were calculated by bootstrapping (50 iterations). We repeated the above analysis only for those with an incident diagnosis of CD within the CPRD UTS period. Finally, for incident CD cases we identified those who had CD symptoms recorded in the year prior to diagnosis. We only included symptoms of diarrhoea, anaemia and weight loss in this subanalysis, because other associated symptoms of tiredness and abdominal pain/ bloating were less specific and susceptible to misclassification. The CIFs and excess risk were then stratified by those with and without having symptoms recorded within a year before diagnosis.

\section{Sensitivity analysis}

We increased the specificity of our case definition by repeating our incidence analyses after restricting our case population to those who in addition to one diagnostic code of CD had either; a relevant prescription for a gluten-free product or a second documented record of their disease.

\section{Ethical statement}

This study was approved by the Independent Scientific Advisory Committee reference number $=10$ 193R.

\section{RESULTS \\ Study population}

Our cohort consisted of 10825 patients with CD frequency matched on age to 107096 people without CD, contributing 60225 and 640086 person years of follow-up times, respectively. The median follow-up from the study start to end dates was calculated to be 5 years (IQR $=2-10$ years). Table 1 presents
Table 1 Basic characteristics of the study population

\begin{tabular}{|c|c|c|c|c|}
\hline \multirow[b]{2}{*}{ Characteristics } & \multicolumn{2}{|l|}{$\begin{array}{l}\text { Without CD } \\
N=107096\end{array}$} & \multicolumn{2}{|l|}{$\begin{array}{l}\text { With CD } \\
N=10825\end{array}$} \\
\hline & No. & Per cent & No. & Per cent \\
\hline \multicolumn{5}{|l|}{ Cohort (n) } \\
\hline Deaths & 9810 & - & 773 & - \\
\hline Person years & 640086 & - & 60225 & - \\
\hline $\begin{array}{l}\text { Median follow-up in } \\
\text { years (IQR) }\end{array}$ & $4.7(1.7-10.1)$ & & $4.6(1.7-9.0)$ & \\
\hline \multicolumn{5}{|l|}{ Sex ( $n=$ patients) } \\
\hline Male & 52401 & 48.9 & 3779 & 34.9 \\
\hline Female & 54695 & 51.1 & 7046 & 65.1 \\
\hline \multicolumn{5}{|c|}{ Age in years* ( $n=$ patients) } \\
\hline$<5$ & 5074 & 4.7 & 373 & 3.4 \\
\hline $5-17$ & 8631 & 8.1 & 1012 & 9.3 \\
\hline $18-29$ & 14698 & 13.7 & 1454 & 13.4 \\
\hline $30-49$ & 35886 & 33.5 & 3599 & 33.2 \\
\hline $50-69$ & 31093 & 29 & 3135 & 29 \\
\hline$>69$ & 11714 & 10.9 & 1252 & 11.6 \\
\hline \multicolumn{5}{|c|}{ SES quintile ( $n=$ patients) } \\
\hline 1 (least deprived) & 24644 & 23.2 & 2946 & 27.5 \\
\hline 2 & 24448 & 23 & 2592 & 24.2 \\
\hline 3 & 20628 & 19.4 & 2111 & 19.7 \\
\hline 4 & 21101 & 19.9 & 1830 & 17.1 \\
\hline 5 (Most deprived) & 15452 & 14.5 & 1253 & 11.7 \\
\hline \multicolumn{5}{|c|}{ Cause of death ( $\mathrm{n}=$ deaths) } \\
\hline Circulatory & 3244 & 33.1 & 209 & 27 \\
\hline Neoplasm & 2763 & 28.2 & 229 & 29.6 \\
\hline Respiratory & 1214 & 12.4 & 103 & 13.3 \\
\hline Digestive & 438 & 4.5 & 52 & 6.7 \\
\hline Neurological & 257 & 2.6 & 21 & 2.7 \\
\hline Genitourinary & 177 & 1.8 & 16 & 2.1 \\
\hline Endocrine & 120 & 1.2 & 15 & 1.9 \\
\hline Psychiatric & 247 & 2.5 & 15 & 1.7 \\
\hline External & 211 & 2.1 & 13 & 1.7 \\
\hline Musculoskeletal & 69 & 0.7 & 10 & 1.3 \\
\hline Other & 344 & 3.5 & 27 & 3.5 \\
\hline Not coded & 726 & 7.4 & 63 & 8.2 \\
\hline
\end{tabular}

the basic demographic characteristics of people with and without $\mathrm{CD}$ along with the number of deaths which occurred under each ICD-10 chapter heading. For the purpose of this study we grouped together chapter headings as 'other causes' for which we had less than 10 deaths per heading in our CD group which also included the symptoms' chapter. The most frequent chapter heading under 'other causes' was 'infection' followed by 'dermatological'. Compared with those without CD, our CD cases were more likely to be women, slightly older and belonging to higher social class.

\section{Crude mortality rate}

Overall, there were 773 deaths among people with CD and 9810 in those without CD, giving overall mortality rates of 128 and 153 per 10000 person years, respectively. These rates were not statistically different after adjusting for age and sex $(\mathrm{HR}=0.94$ (95\% CI 0.84 to 1.01$))$. Table 2 shows the mortality rates stratified by ICD-10 chapter headings. Overall the rate of death from neoplasm among those with $\mathrm{CD}$ compared with 
Table 2 Mortality rates per 10000 person years stratified by International Classification of Diseases V.2010 (ICD-10) headings

\begin{tabular}{|c|c|c|c|c|c|c|c|c|}
\hline \multirow{3}{*}{$\begin{array}{l}\text { Cause of death } \\
\text { Overall mortality }\end{array}$} & \multicolumn{4}{|c|}{ With CD } & \multicolumn{4}{|c|}{ Without CD } \\
\hline & \multirow{2}{*}{$\begin{array}{l}\mathbf{n} \\
773\end{array}$} & \multirow{2}{*}{$\begin{array}{l}\text { Rate } \\
128\end{array}$} & \multicolumn{2}{|c|}{$95 \% \mathrm{Cl}$} & \multirow{2}{*}{$\begin{array}{l}\mathbf{n} \\
9810\end{array}$} & \multirow{2}{*}{$\begin{array}{l}\text { Rate } \\
153\end{array}$} & \multicolumn{2}{|l|}{$95 \% \mathrm{Cl}$} \\
\hline & & & 119 & 137 & & & 150 & 156 \\
\hline Neoplasm overall & 229 & 38.0 & 33.4 & 43.3 & 2763 & 43.2 & 41.6 & 44.8 \\
\hline Oesophagus/stomach & 21 & 3.5 & 2.3 & 5.3 & 210 & 3.3 & 2.9 & 3.8 \\
\hline Colon & 19 & 3.2 & 2.0 & 4.9 & 151 & 2.4 & 2.0 & 2.8 \\
\hline Pancreas & 19 & 3.2 & 2.0 & 4.9 & 144 & 2.2 & 1.9 & 2.6 \\
\hline Digestive (other) & 16 & 2.7 & 1.6 & 4.3 & 187 & 2.9 & 2.5 & 3.4 \\
\hline Respiratory & 39 & 6.5 & 4.7 & 8.9 & 604 & 9.4 & 8.7 & 10.2 \\
\hline Skin/bone/breast & 14 & 2.3 & 1.4 & 3.9 & 316 & 4.9 & 4.4 & 5.5 \\
\hline Prostrate & 10 & 1.7 & 0.9 & 3.1 & 212 & 3.3 & 2.9 & 3.8 \\
\hline Non-Hodgkin's lymphoma & 26 & 4.3 & 2.9 & 6.3 & 90 & 1.4 & 1.1 & 1.7 \\
\hline Leukaemia & 7 & 1.2 & 0.6 & 2.4 & 78 & 1.2 & 1.0 & 1.5 \\
\hline Other or benign & 58 & 9.6 & 7.4 & 12.5 & 772 & 12.1 & 11.2 & 12.9 \\
\hline Cardiovascular overall & 209 & 34.7 & 30.3 & 39.7 & 3244 & 50.7 & 49.0 & 52.5 \\
\hline IHD & 72 & 12.0 & 9.5 & 15.1 & 1303 & 20.4 & 19.3 & 21.5 \\
\hline Heart-other & 29 & 4.8 & 3.3 & 6.9 & 512 & 8.0 & 7.3 & 8.7 \\
\hline CVA & 81 & 13.4 & 10.8 & 16.7 & 833 & 13.0 & 12.2 & 13.9 \\
\hline Other-circulatory & 27 & 4.5 & 3.1 & 6.5 & 596 & 9.3 & 8.6 & 10.1 \\
\hline Respiratory overall & 103 & 17.1 & 14.1 & 20.7 & 1214 & 19.0 & 17.9 & 20.1 \\
\hline Respiratory infection & 37 & 6.1 & 4.5 & 8.5 & 439 & 6.9 & 6.2 & 7.5 \\
\hline Chronic airway disease & 39 & 6.5 & 4.7 & 8.9 & 414 & 6.5 & 5.9 & 7.1 \\
\hline Respiratory-other & 27 & 4.5 & 3.1 & 6.5 & 361 & 5.6 & 5.1 & 6.3 \\
\hline Digestive overall & 52 & 8.6 & 6.6 & 11.3 & 438 & 6.8 & 6.2 & 7.5 \\
\hline Upper-GI & 2 & 0.3 & 0.1 & 1.3 & 98 & 1.5 & 1.3 & 1.9 \\
\hline Lower-GI & 17 & 2.8 & 1.8 & 4.5 & 188 & 2.9 & 2.5 & 3.4 \\
\hline Liver/gall bladder/pancreas & 22 & 3.7 & 2.4 & 5.5 & 148 & 2.3 & 2.0 & 2.7 \\
\hline Digestive-other & 11 & 1.8 & 1.0 & 3.3 & 4 & 0.1 & 0.0 & 0.2 \\
\hline Neurological & 21 & 3.5 & 2.3 & 5.3 & 257 & 4.0 & 3.6 & 4.5 \\
\hline Genitourinary & 16 & 2.7 & 1.6 & 4.3 & 177 & 2.8 & 2.4 & 3.2 \\
\hline Endocrine & 15 & 2.5 & 1.5 & 4.1 & 120 & 1.9 & 1.6 & 2.2 \\
\hline Psychiatric & 15 & 2.5 & 1.5 & 4.1 & 247 & 3.9 & 3.4 & 4.4 \\
\hline External & 13 & 2.2 & 1.3 & 3.7 & 211 & 3.3 & 2.9 & 3.8 \\
\hline Other & 37 & 6.1 & 4.5 & 8.5 & 413 & 6.5 & 5.9 & 7.1 \\
\hline Not coded & 63 & 10.5 & 8.2 & 13.4 & 726 & 11.3 & 10.5 & 12.2 \\
\hline
\end{tabular}

CD, coeliac disease; CVA, cerebrovascular accident; IHD, ischaemic heart disease.

those without CD was broadly similar (38 vs 43 per 10000 person years). However, non-Hodgkin's lymphoma was associated with an absolute excess mortality rate of 3 per 10000 person years compared with those without CD (absolute rate $=4.3$ vs 1.4 per 10000 person years). CD cases had a slightly lower rate of dying from breast, respiratory and prostate cancers (absolute rate $=1.3,6.5$ and 0.17 per 10000 person years, respectively). Patients with CD also had an overall lower rate of death from cardiovascular disease compared with our control population (35 vs 51 per 10000 person years), but had higher risk of dying from digestive diseases ( 9 vs 7 per 10000 person years).

\section{Cumulative incidence function}

The above crude comparisons were not adjusted for age or competing risks. We therefore determined the CIF of death for the most frequent causes of death by ICD-10 chapter heading after accounting for competing events (table 3). While the median follow-up for our study was around 5 years, patients could enter and leave the follow-up to contribute their average of 5 years at any point in the subsequent 10 years after $\mathrm{CD}$ diagnosis. This open cohort method allowed us to calculate cumulative incidence of death by 10 years after $\mathrm{CD}$ diagnosis. The cumulative incidence of cardiovascular death by 10 years post diagnosis was slightly lower for those with $\mathrm{CD}$ compared with controls $(3.35 \%$ vs $4.72 \%)$ which corresponded to an excess CI of $-1.38 \%$ (95\% CI -1.91 to -0.85$)$. We observed that those between the ages of 60-79 years had around 3\% lower risk of cardiovascular deaths by 10 years after CD diagnosis. Similarly, those over the age of 80 years had 3\% lower risk of respiratory disease related deaths whereas those under the age of 50 years had a very slight excess risk $(0.18 \%)$ of respiratory disease related deaths.

After adjusting cumulative incidence for competing events, sex, SES and age, the overall cumulative incidence of death by 10 years was calculated to be $2 \%$ among those with $C D$ (figure 1). We observed that there were no statistically significant differences for the overall cancer, digestive disease or respiratory disease related mortality among those with and without $C D$ (table 4). However, patients with $\mathrm{CD}$ had a slightly lower risk of cardiovascular deaths (excess CI $-0.08 \% 95 \%$ CI -0.13 to $-0.04)$. Within neoplasm, we found that the cumulative incidence of deaths from non-Hodgkin's lymphoma was higher for our case population corresponding to an excess CI of $0.15 \%$ 
Table 3 Cumulative incidence function and excess risk by 10 years post coeliac disease (CD) diagnosis adjusting for competing risk. The results are stratified by age at diagnosis

\begin{tabular}{|c|c|c|c|c|c|}
\hline Cause of death & $\begin{array}{l}\text { With } \\
\text { CD }\end{array}$ & $\begin{array}{l}\text { Without } \\
\text { CD }\end{array}$ & Excess & $95 \% \mathrm{Cl}^{*}$ & \\
\hline $\begin{array}{l}\text { Cardiovascular overall } \\
\text { (years) }\end{array}$ & 3.35 & 4.72 & -1.38 & -1.91 & -0.85 \\
\hline$\leq 50$ & 0.38 & 0.31 & 0.07 & -0.18 & 0.33 \\
\hline $50-59$ & 1.64 & 1.93 & -0.28 & -1.05 & 0.48 \\
\hline $60-69$ & 3.55 & 6.28 & -2.73 & -4.19 & -1.27 \\
\hline $70-79$ & 13.14 & 16.63 & -3.49 & -6.35 & -0.64 \\
\hline$\geq 80$ & 27.99 & 32.39 & -4.40 & -10.30 & 1.51 \\
\hline Respiratory overall (years) & 1.55 & 1.70 & -0.15 & -0.52 & 0.21 \\
\hline$\leq 50$ & 0.25 & 0.07 & 0.18 & 0.00 & 0.35 \\
\hline $50-59$ & 0.61 & 0.57 & 0.05 & -0.53 & 0.62 \\
\hline $60-69$ & 2.19 & 1.87 & 0.32 & -0.78 & 1.42 \\
\hline $70-79$ & 6.76 & 6.47 & 0.29 & -2.13 & 2.71 \\
\hline$\geq 80$ & 9.87 & 13.13 & -3.26 & -6.28 & -0.25 \\
\hline Neoplasm overall (years) & 3.78 & 4.09 & -0.31 & -0.87 & 0.26 \\
\hline$\leq 50$ & 0.88 & 0.61 & 0.27 & -0.11 & 0.65 \\
\hline $50-59$ & 3.83 & 3.28 & 0.55 & -0.58 & 1.68 \\
\hline $60-69$ & 7.59 & 8.04 & -0.45 & -2.41 & 1.51 \\
\hline $70-79$ & 11.61 & 12.05 & -0.45 & -3.25 & 2.36 \\
\hline$\geq 80$ & 10.31 & 12.52 & -2.22 & -6.01 & 1.57 \\
\hline Digestive overall (years) & 0.85 & 0.65 & 0.20 & -0.07 & 0.48 \\
\hline$\leq 50$ & 0.37 & 0.14 & 0.23 & -0.03 & 0.48 \\
\hline $50-59$ & 0.94 & 0.44 & 0.50 & 0.00 & 0.99 \\
\hline $60-69$ & 1.55 & 0.83 & 0.73 & -0.13 & 1.58 \\
\hline $70-79$ & 1.36 & 1.82 & -0.47 & -1.52 & 0.59 \\
\hline$\geq 80$ & 3.26 & 3.55 & -0.29 & -2.93 & 2.34 \\
\hline Others overall (years) & 1.78 & 2.03 & -0.25 & -0.62 & 0.12 \\
\hline$\leq 50$ & 0.46 & 0.43 & 0.02 & -0.22 & 0.27 \\
\hline $50-59$ & 0.93 & 0.74 & 0.20 & -0.46 & 0.86 \\
\hline $60-69$ & 1.08 & 1.65 & -0.57 & -1.45 & 0.30 \\
\hline $70-79$ & 4.89 & 5.94 & -1.06 & -3.11 & 1.00 \\
\hline$\geq 80$ & 19.30 & 17.80 & 1.51 & -3.53 & 6.54 \\
\hline Not coded overall & 0.81 & 0.84 & -0.03 & -0.28 & 0.23 \\
\hline
\end{tabular}

(95\% CI 0.03 to 0.27 ). Our cumulative incidence up to 10 years remained fairly similar when we restricted our analysis to only incidence cases and stratified by those with and without symptoms recorded within a year before CD diagnosis (table 5).

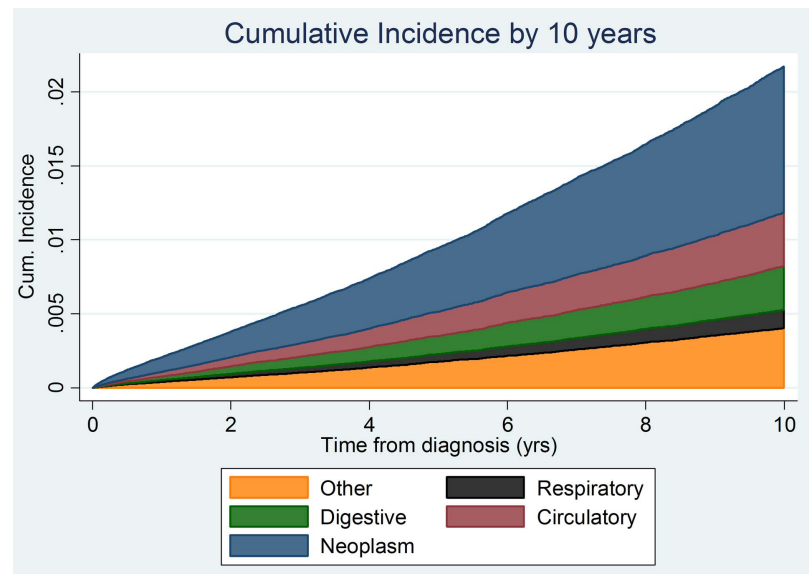

Figure 1 Cumulative incidence by time after diagnosis, adjusting for competing events, age and sex.
Table 4 Cumulative incidence function by 10 years of diagnosis adjusted for competing risk, age, socioeconomic status and gender

\begin{tabular}{lllrrr}
\hline Cause of death & $\begin{array}{l}\text { With } \\
\text { CD }\end{array}$ & $\begin{array}{l}\text { Without } \\
\text { CD }\end{array}$ & Excess & 95\% Cl* \\
\hline Cardiovascular & 0.32 & 0.41 & -0.08 & -0.13 & -0.04 \\
$\quad$ Ischemic heart disease & 0.15 & 0.26 & -0.05 & -0.10 & -0.00 \\
Respiratory & 0.11 & 0.10 & 0.00 & -0.02 & 0.03 \\
$\quad$ Respiratory infection & 0.16 & 0.20 & -0.04 & -0.09 & 0.01 \\
Neoplasm & 1.24 & 1.21 & 0.04 & -0.10 & 0.18 \\
$\quad$ Non-Hodgkin's lymphoma & 0.21 & 0.06 & 0.15 & 0.03 & 0.27 \\
Digestive & 0.24 & 0.16 & 0.07 & -0.01 & 0.16 \\
Others & 0.27 & 0.29 & -0.02 & -0.07 & 0.04 \\
Not coded & 0.27 & 0.25 & 0.02 & -0.07 & 0.10 \\
\hline
\end{tabular}

*Bootstrap 50 iterations.

CD, coeliac disease.

\section{Sensitivity analysis}

Seventy-six per cent of our CD cases received a relevant prescription for a gluten-free product and/or a second documented record of their disease. We found that our overall and cause-specific mortality rates remained unchanged when we applied our restrictive case definition (see online supplementary table S1).

\section{DISCUSSION}

\section{Main findings}

We have calculated the excess cumulative incidence of death following a diagnosis of $\mathrm{CD}$ compared with the general

Table 5 Cumulative incidence function (CIF) by 10 years of diagnosis adjusted for competing risk, age, socioeconomic status and gender

\begin{tabular}{|c|c|c|c|c|c|}
\hline Cause of death & $\begin{array}{l}\text { Deaths } \\
\mathrm{n}\end{array}$ & $\begin{array}{l}\text { CIF } \\
\text { with CD }\end{array}$ & Excess* & \multicolumn{2}{|l|}{$95 \% \mathrm{Clt}$} \\
\hline \multicolumn{6}{|c|}{ Restricting to only incident cases (overall CD cases $=4687$ ) } \\
\hline Cardiovascular & 72 & 0.27 & -0.13 & -0.19 & -0.07 \\
\hline Respiratory & 30 & 0.07 & -0.02 & -0.05 & 0.01 \\
\hline Neoplasm & 86 & 1.12 & -0.05 & -0.33 & 0.22 \\
\hline Digestive & 18 & 0.19 & 0.04 & -0.04 & 0.13 \\
\hline Others & 38 & 0.22 & -0.06 & -0.14 & 0.01 \\
\hline Not coded & 27 & 0.30 & 0.04 & -0.09 & 0.17 \\
\hline \multicolumn{6}{|c|}{ Restricting to symptomatic incident cases (overall CD cases $=1895$ ) } \\
\hline Cardiovascular & 34 & 0.25 & -0.16 & -0.24 & -0.07 \\
\hline Respiratory & 16 & 0.08 & -0.02 & -0.06 & 0.01 \\
\hline Neoplasm & 36 & 0.97 & -0.20 & -0.51 & 0.12 \\
\hline Digestive & 7 & 0.15 & 0.00 & -0.08 & 0.09 \\
\hline Others & 15 & 0.17 & -0.11 & -0.19 & -0.03 \\
\hline Not coded & 13 & 0.29 & 0.04 & -0.11 & 0.18 \\
\hline \multicolumn{6}{|c|}{ Restricting to non-symptomatic incident cases (overall CD cases $=2792$ ) } \\
\hline Cardiovascular & 38 & 0.29 & -0.11 & -0.20 & -0.01 \\
\hline Respiratory & 14 & 0.07 & -0.02 & -0.07 & 0.03 \\
\hline Neoplasm & 50 & 1.25 & 0.09 & -0.30 & 0.47 \\
\hline Digestive & 11 & 0.22 & 0.08 & -0.05 & 0.20 \\
\hline Others & 23 & 0.28 & -0.01 & -0.13 & 0.10 \\
\hline Not coded & 14 & 0.30 & 0.04 & -0.13 & 0.22 \\
\hline
\end{tabular}


population. We have done this in a large unselected cohort of more than 10000 patients with $\mathrm{CD}$ and assessed the underlying cause while accounting for competing events. Our analysis showed no overall excess risk of cancer, digestive disease or respiratory disease related, or cardiovascular mortality after adjusting for age and sex. In fact, those with $\mathrm{CD}$ had a slightly lower cumulative incidence of cardiovascular death following diagnosis. Finally, we observed that patients with $\mathrm{CD}$ had a $0.15 \%$ excess risk of dying from non-Hodgkin's lymphoma up to 10 years post diagnosis.

\section{Strengths and limitations}

Our study used information on more than 10000 patients with $\mathrm{CD}$ diagnosis to analyse excess cumulative incidence of causespecific deaths compared with those without CD in England. The use of this contemporary, nationally representative primary care data makes our study findings generalisable to patients with clinically diagnosed CD in the UK and allows comparisons with the only other similar data available on this subject, which comes from Sweden. ${ }^{78}$ Furthermore, we had a large sample size and prospective follow-up, and were able to adjust for competing events which allowed us to calculate accurate, unbiased and more detailed cause-specific cumulative mortality rates than most previous studies done on the subject.

A potential weakness of conducting epidemiological studies using routinely collected data is the validity of the diagnostic data for each patient. However, the diagnosis of CD has been validated in these data with a positive predictive value ranging between $81 \%$ and $100 \% .{ }^{16}$ We found that our cause-specific absolute mortality rates remained unchanged when we restricted our analysis to CD cases who had either a gluten-free prescription or more than one $\mathrm{CD}$ diagnostic code in their medical records. Previous studies suggest that of the $1 \%$ of the general population that have a positive serology for $\mathrm{CD}$ only about $0.2 \%$ are clinically diagnosed in the UK. ${ }^{1}{ }^{17}{ }^{18}$ Therefore it is possible that there may be people with undiagnosed $\mathrm{CD}$ in our comparison cohort and it may be argued that we failed to observe excess cause-specific mortality because of the undetected $\mathrm{CD}$ in our control population. We believe that the impact of this limitation will however be minimal as a previous study by our group ${ }^{19}$ found no difference in the overall and cause-specific mortality among those with undetected CD compared with the general population in England. We acknowledge that our comparison group may include some patients with IBS. However it is very unlikely that this would influence our estimates given that there is no evidence that IBS is associated with increased mortality risk. In our study we found that $6 \%$ of our comparison group had a diagnosis of IBS, ${ }^{20}$ however, our mortality data remained unaltered when we excluded those patients from our analysis.

Cause of death information in our study was from the ONS death register which uses standardised WHO guidelines to extract information on cause of death from the death certificates. It is important to note that death certificates may be imprecise, yet they are the official legal requirement for ascertaining the cause of death. As a consequence, death certificates are the only standard method to extract information on the cause of death across such a large population as we have used. For the purpose of this study we only used the underlying cause of death information to avoid changes in the coding requirements over time.

Our study also lacked compliance data on a gluten-free diet among those with CD. Corrao $e t a l^{4}$ previously demonstrated higher overall mortality among those who were less adherent to a gluten-free diet compared with those who were more adherent. However their study only included a selected group of patents identified from hospital and therefore results may not be generalisable. While our study is one of the largest to look at the mortality among patients with celiac disease, our median follow-up was only 5 years $(\mathrm{IQR}=1.7-10)$. Therefore we acknowledge that we may not have been able to capture the very long-term consequences of the disease.

\section{Other studies}

We have conducted the first study which has looked at the excess risk of cause-specific death among people with $\mathrm{CD}$ while taking into account competing risks. Although there are no other reports available that have carried out such an analysis our overall and cause-specific mortality rates are in concordance with the most contemporary evidence on the subject. For instance, we found neoplasm to be the most common cause of death among patients with $\mathrm{CD}$ followed by cardiovascular disease which is broadly consistent with other population based studies from the UK. ${ }^{6}$

Overall, we found no excess risk of neoplasm related mortality among patients with $\mathrm{CD}$, a finding which contradicts the conclusion of most previous studies. ${ }^{6-9} 21$ For instance, the largest study by Ludvigsson et $a l^{8}$ reported a $55 \%$ relative increased risk of neoplasm related deaths among patients with CD compared with controls which is in line with other UK based studies by Grainge et $a l^{9}$ and Solaymani-Dodaran et al. ${ }^{6}$ This may be due to the fact that the previous studies did not adjust for the risk of dying from other causes or that the Swedish data had a far greater proportion of children in it than ours and the Lothian and Derby studies had cohorts which were mainly diagnosed before the year 2000. The unadjusted estimates handle death from other causes as censoring which assumes that the risk of death for the people who die is the same as for the people who did not die. In most scenarios this does not make biological sense. ${ }^{22}$ Furthermore, not adequately adjusting for competing risk of death can result in considerable overestimation (depending on the duration of follow-up) of cause-specific death rates which can give misleading results when comparing the occurrence of an outcome of interest. After adjusting for competing risks, we did identify a statistically significant excess risk of death from non-Hodgkin's lymphoma $(<0.1 \%)$ which is consistent with other studies. ${ }^{4-7} 9$

We observed a slightly lower risk of cardiovascular deaths among those with CD. This finding is supported by another population based study by West et $a l^{23}$ who reported a lower prevalence of hypertension and hypercholesterolaemia compared with the general population using the same database. Our study showed no statistically significant excessive risk of nonmalignant digestive disease or respiratory disease related deaths among patients with $\mathrm{CD}$. In contrast, a previous study from Sweden $^{8}$ reported a $36 \%$ increased risk of respiratory disease related mortality. Finally, Grainge et $a l^{9}$ reported a fourfold increased risk of non-malignant digestive disease related deaths among patients with $\mathrm{CD}$. However their results were based on few cases $(n=10)$ giving a wide CI. Moreover, the likelihood of detecting $\mathrm{CD}$ may increase during the investigation for other digestive diseases, therefore the excess risk of digestive disease related mortality observed in the previous study may be attributable to more detailed investigations being carried out among those patients, that is, an ascertainment bias phenomenon. 


\section{Implications}

Our study has demonstrated that patients with CD have no major excessive risk of cancer, digestive disease or respiratory disease related, or cardiovascular mortality compared with the general population. There is an excess risk of dying of non-Hodgkin's lymphoma among patients with CD but the excess cumulative risk is very small indeed. Overall our findings are reassuring to patients with $\mathrm{CD}$ and clinicians managing their care.

Contributors AAS and JW conceived the idea for the study, with KMF, CJC, TC and LJT also making important contributions to the design of the study. AAS carried out the data management and analysis and wrote the first draft of the manuscript. All authors were involved in the interpretation of the data, contributed towards critical revision of the manuscript and approved the final draft. AAS had full access to all of the data and final responsibility for the decision to submit for publication.

Funding CORE/Coeliac UK; JW is funded by a University Of Nottingham/ Nottingham University Hospitals NHS Trust Senior Clinical Research Fellowship.

Ethics approval Independent Scientific Advisory Committee (ISAC) reference number=10_193R.

Provenance and peer review Not commissioned; externally peer reviewed.

Open Access This is an Open Access article distributed in accordance with the Creative Commons Attribution Non Commercial (CC BY-NC 4.0) license, which permits others to distribute, remix, adapt, build upon this work non-commercially, and license their derivative works on different terms, provided the original work is properly cited and the use is non-commercial. See: http://creativecommons.org/ licenses/by-nc/4.0/

\section{REFERENCES}

1 West J, Fleming KM, Tata LJ, et al. Incidence and prevalence of celiac disease and dermatitis herpetiformis in the UK over two decades: population-based study. Am J Gastroenterol 2014;109:757-68.

2 Dubé C, Rostom A, Sy R, et al. The prevalence of celiac disease in average-risk and at-risk Western European populations: a systematic review. Gastroenterology 2005; 128:S57-67.

3 Tio M, Cox M, Eslick G. Meta-analysis: coeliac disease and the risk of all-cause mortality, any malignancy and lymphoid malignancy. Aliment Pharmacol Ther 2012:35:540-51.

4 Corrao G, Corazza GR, Bagnardi V, et al. Mortality in patients with coeliac disease and their relatives: a cohort study. Lancet 2001;358:356-61.
5 Cottone M, Termini A, Oliva L, et al. Mortality and causes of death in celiac disease in a Mediterranean area. Dig Dis Sci 1999;44:2538-41.

6 Solaymani-Dodaran M, West J, Logan RF. Long-term mortality in people with celiac disease diagnosed in childhood compared with adulthood: a population-based cohort study. Am J Gastroenterol 2007;102:864-70.

7 Peters U, Askling J, Gridley G, et al. Causes of death in patients with celiac disease in a population-based Swedish cohort. Arch Intern Med 2003;163:1566-72.

8 Ludvigsson JF, Montgomery SM, Ekbom A, et al. Small-intestinal histopathology and mortality risk in celiac disease. JAMA 2009;302:1171-8.

9 Grainge MJ, West J, Card TR, et al. Causes of death in people with celiac disease spanning the pre-and post-serology era: a population-based cohort study from Derby, UK. Am J Gastroenterol 2011;106:933-9.

10 Logan RFA, Rifkind EA, Turner ID, et al. Mortality in celiac disease. Gastroenterology 1989;97:265-71.

11 Clinical Practice Research Database. http://www.cprd.com/intro.asp (accessed 19 Apr 2013).

12 National Health Service. Information centre. Final general practice registered populations 2011. http://www.ic.nhs.uk/statistics-and-data-collections/ population-and-geography/gp-registered-populations/attribution-datasetgpregistered-populationscaledto-ons-population-estimates-201 (accessed $23 \mathrm{Apr}$ 2014).

13 Williams T, Van Staa T, Puri S, et al. Recent advances in the utility and use of the General Practice Research Database as an example of a UK Primary Care Data resource. Ther Adv Drug Saf 2012;3:89-99.

14 World Health Organisation. International classification of disease and related health problems. Tenth revision. 2nd edn. Geneva: WHO, 2004:31-92.

15 Andersen PK, Geskus RB, de Witte T, et al. Competing risks in epidemiology: possibilities and pitfalls. Int J Epidemiol 2012;41:861-70.

16 West J. Coeliac disease: studies of its frequency and consequence. PhD Thesis. The University of Nottingham, 2005.

17 Bingley PJ, Norcross AJ, Lock RJ, et al. Undiagnosed coeliac disease at age seven: population based prospective birth cohort study. BMJ 2004;328:322-3.

18 West J, Logan RFA, Hill PG, et al. Seroprevalence, correlates, and characteristics of undetected coeliac disease in England. Gut 2003;52:960-5.

19 Canavan C, Logan R, Khaw KT, et al. No difference in mortality in undetected coeliac disease compared with the general population: a UK cohort study. Aliment Pharmacol Ther 2011;34:1012-19.

20 Canavan C, West J, Card T. The epidemiology of irritable bowel syndrome. Clin Epidemiol 2014;6:71-80.

21 West J, Logan RF, Smith CJ, et al. Malignancy and mortality in people with coeliac disease: population based cohort study. BMJ 2004;329:716-19.

22 Yan Y, Moore RD, Hoover DR. Competing risk adjustment reduces overestimation of opportunistic infection rates in AIDS. J Clin Epidemiol 2000;53:817-22.

23 West J, Logan R, Card T, et al. Risk of vascular disease in adults with diagnosed coeliac disease: a population-based study. Aliment Pharmacol Ther 2004;20:73-9. 